Bull. Mater. Sci, Vol. 3, Number 3, November 1981, pp. 333-339. o Printed in India

\title{
Moisture absorption and its effect on the electrical properties of high silica fabric
}

\author{
B E RAMA CHANDRAN, N BALASUBRAMANIAN \\ G V SUBBA RAO* and G ARAVAMUDAN* \\ Materials Science Division, National Aeronautical Laboratory, \\ Bangalore 560 017, India \\ * Materials Science Research Centre, Indian Institute of Technology, \\ Madras 600036 , India
}

MS received 16 March 1981

\begin{abstract}
High silica fabric with a silica content $>98 \%$ can be prepared by removing the non-siliceous ions from the E-glass fabric using $\mathrm{HCl}$ as the leachant. The presence of Si-OH groups makes the material hydrophilic. The extent of moisture absorption depends on the extent of leaching. The moisture present in the leached fabric decreases the volume and surface resistivity values.
\end{abstract}

Keywords. Porosity; moisture absorption; diffusion; silanol groups; volume resistivity; surface resistivity.

\section{Introduction}

The absorption of water molecules to the glass surface or the absorption in the bulk material is of both practical importance and academic interest. When glass is used for vacuum envelopes and insulating the electrodes in vacuum devices, a knowledge of moisture absorption characteristics is important (Holland 1966). Alkali silicate glasses with alkali content greater than $20 \%$ have such poor resistance to water attack that they can be completely dissolved in water to form water glass. Various glass compositions show different types of hydration (Che-Kvang Wu 1980). The absorption of water vapour on glass surface is due partly to a firmly held (chemisorbed) monolayer which cannot be removed by pumping at room temperature and partly to a physically adsorbed film (Razouk and Salem 1948).

In the presence of atmospheric moisture the silica of the glass surface will rapidly be transformed into the hydroxylate state. The hydration process will not stop with the formation of silanol groups, since they can form hydrogen bond with water to multimolecular layer of absorbate over the surface. Studies on E-glass showed the surface coverage of $1,3,5$ monolayer of water at relative humidity 10,50,60 respectively (Broutman and Krock 1968: Gut Friend and Weber 1961). It was proved experimentally that water vapour absorption is 
restricted to silanol sites on the glass surface even at high relative pressures (Young 1958). Various reviews are available on the interaction of water with glass (Scholze 1966; Moulson and Roberts 1961 ; Hvang 1971).

The moisture absorbed by the glass plays a vital role in effecting various of physical properties of the glass. Excellent reports are available on the effect of water on the properties of glass (Boulos and Kreidl 1972; Scholze 1966; Hetherington and Jack 1962).

It is generally agreed that water is mostly accommodated in the glass structure in the form of hydroxyl ions and a reaction of the type,

$$
(\equiv \mathrm{Si}-\mathrm{O}-\mathrm{Si} \equiv)+\mathrm{H}_{2} \mathrm{O} \rightleftharpoons 2(\equiv \mathrm{Si}-\mathrm{OH})
$$

is generally postulated. Silanol group formation is also observed when the glass reacts with acids or alkalies

$$
\begin{aligned}
& (\equiv \mathrm{Si}-\mathrm{O}-)_{\mathrm{n}} \mathrm{M}^{\mathrm{n}+}+\mathrm{nH}^{+} \rightleftharpoons n(\equiv \mathrm{Si}-\mathrm{OH})+\mathrm{M}^{\mathrm{n}+} \\
& (\equiv \mathrm{Si}-\mathrm{O}-\mathrm{Si} \equiv)+\mathrm{OH}^{-} \rightleftharpoons(\equiv \mathrm{Si}-\mathrm{OH})+\left(\equiv \mathrm{Si}_{-} \mathrm{O}^{-}\right)
\end{aligned}
$$

The silanol groups thus formed become the hydrophilic sites.

In the present work E-glass fabrics were leached in different normalities of $\mathrm{HCl}$ for a fixed time $(4 \mathrm{hr})$, to remove the nonsiliceous ions and to create silanol groups. The moisture content and moisture absorption against time was studied. The effect of moisture on volume and surface resistivity was also studied. Protonic conduction was found to dominate in these high silica glass. Leaching studies on E-glass was carried out to prepare high silica glass (silica content $>98 \%$ ). This material is used as a high temperature electrical and thermal insulator. It is used in rocket nozzles for ablative purposes and in furnaces for thermal insulation.

\section{Experimental}

E-glass fabric (Pilkington, UK composition) was employed in the present work. The composition ascertained by the chemical analysis was, $\mathrm{SiO}_{2}, 54 \cdot 2 ; \mathrm{Al}_{2} \mathrm{O}_{3}, 14$; $\mathrm{CaO}, 19 \cdot 8 ; \mathrm{MgO}, 2 \cdot 2 ; \mathrm{B}_{2} \mathrm{O}_{3}, 8 \cdot 2 ; \mathrm{Fe}_{2} \mathrm{O}_{3}, 0.3 ; \mathrm{Na}_{2} \mathrm{O}+\mathrm{K}_{2} \mathrm{O}, 0.56$ (all wt \%). The cut fabric pieces were leached in $\mathrm{HCl}$ solution for $4 \mathrm{hr}$. The normality of the solution was varied from $0.5 \mathrm{~N}$ to $4 \mathrm{~N}$. The leached fabrics were heated to various temperatures (post-heat treatment $100-700^{\circ} \mathrm{C}$ ) for $4 \mathrm{hr}$ to remove the absorbed water in an oxidizing atmosphere. It was then cooled to room temperature in a desiccator and then weighed to find the weight loss. The same fabric was exposed to atmosphere of known humidity and the weight increase due to moisture absorption was also recorded.

In addition to moisture absorption experiments, leached and heat-treated fabrics were also used to measure volume and surface resistivity. Details of the equipment and procedure employed have been described earlier (Rama Chandran et al 1980). 


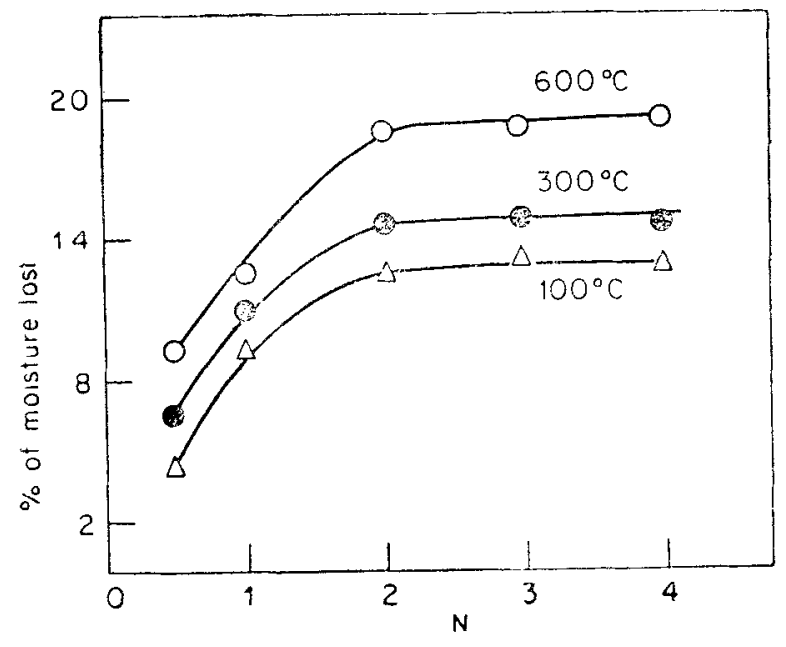

Figare 1. Percentage of moisture lost by the leached fabric $(0.5-4 \mathrm{~N})$ at various temperatures of heat treatment. Leaching time $4 \mathrm{hr}$.

\section{Results and discussion}

As indicated in equation (2), silanol groups can be formed by the removal of non-siliceous ions. These silanol groups tecome the potential sites for water absorption. The silanol group formed can be dehydrated by heating (equation I.) A part from the formation of silanol groups, due to the substitution of smaller $\mathrm{H}^{+}$ ions in place of cations such as $\mathrm{Ca}^{2+}$ and $\mathrm{Al}^{2+}$, the material becomes porous. The porous structure and silanol groups enable water absorption. During the post heat treatment, in addition to the water removal, the pore size distribution is also altered either by shrinkage and/or by the closure of the pores.

\subsection{Moisture content}

The moisture in the leached fabric depends on the number of silanol groups, which in turn depends on the numter of cations removed. The ion removed depends on the concentration of the acid employed for the leaching treatment. Greater the concentration of the acid greater will be the moisture content as the leaching rate decreases. Figure 1 shows this effect at any fixed temperature for fabrics prepared by leaching in $4 \mathrm{~N} \mathrm{HCl}$ for $4 \mathrm{hr}$. As the heat treatment temperature increases, the moisture lost at any fixed normality also increases.

\subsection{Moisture regained}

Figures 2 and 3 show the moisture reabsorption pattern for fabrics leached in $4 \mathrm{~N}$ and $1 \mathrm{~N} \mathrm{HCl}$ for $4 \mathrm{hr}$ and heat-treated to various temperatures for $4 \mathrm{hr}$. The heattreated fabric can absorb moisture again when exposed to the atmosphere. The desorption-absorption process is reversible up to a heat-treatment temperature of 


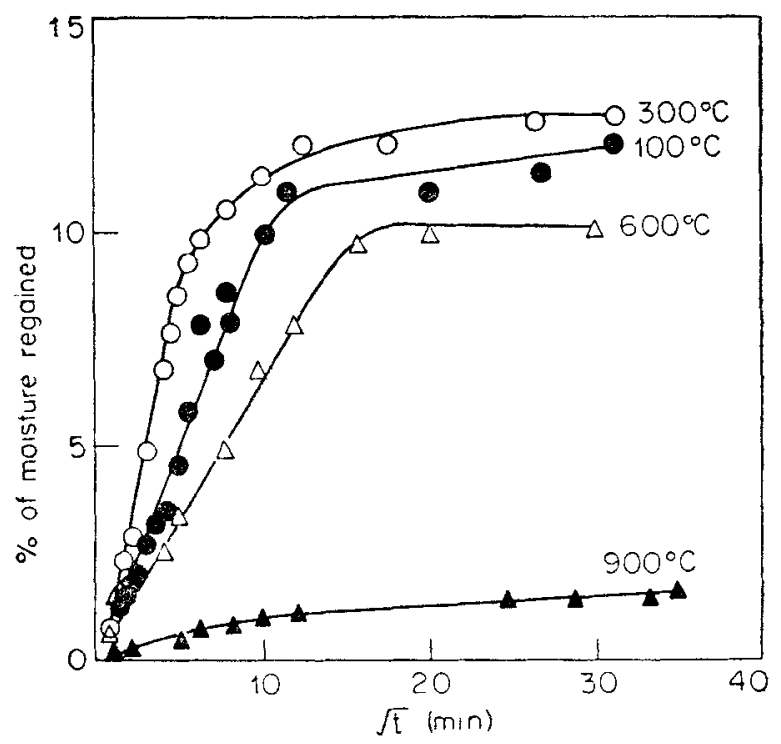

Figure 2. Percentage of moisture regained with time byfabrics leached in $4 \mathrm{~N}$ $\mathrm{HCl}$ for $4 \mathrm{hr}$ and heat-treated to various temperatures.

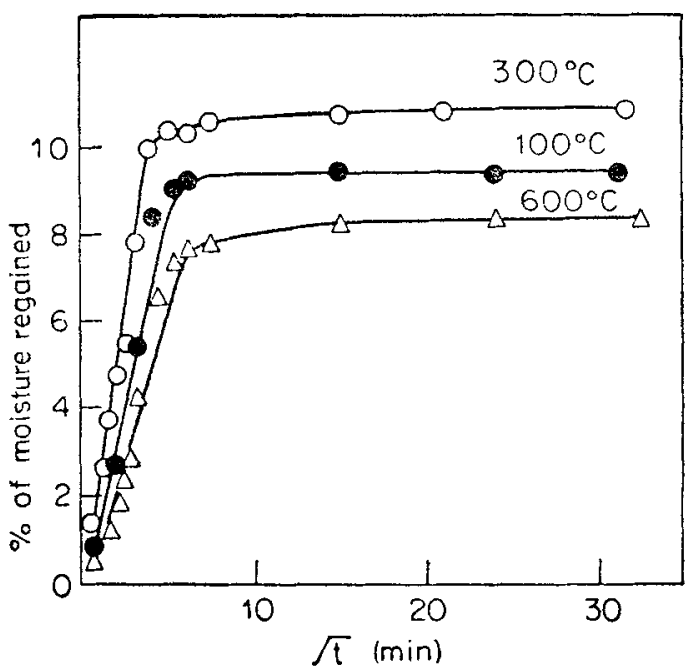

Figuie 3. Percentage of moisture regained with time by fabrics leached in $1 \mathrm{~N}$ $\mathrm{HCl}$ for $4 \mathrm{hr}$ and heat-treated to various temperatures.

$900^{\circ} \mathrm{C}$. The reabsorption is a diffusion-controlled process (Hvang 1971). A heattreatment of $100^{\circ} \mathrm{C}$ removes only physisorbed water, $300^{\circ} \mathrm{C}$ heat treatment removes completely absorbed water and a major portion of structural water by the interaction of $-\mathrm{Si}-\mathrm{OH}$ groups. Heat treatment of $600^{\circ} \mathrm{C}$ leads to partial sintering as well. At $900^{\circ} \mathrm{C}$ the sintering process is completed and hydrophilicity of the material is minimized. 
The fabric heat-treated to $100^{\circ} \mathrm{C}$ loses physically adsorbed water only while structural water (in the form of silanol group) remains in tact in the material. On exposure it recaptures only the free absorbed water. A $300^{\circ} \mathrm{C}$ heat-treated fabric loses all the adsorbed water and structural water and recaptures it again. Hence the moisture lost and regained will be higher compared to $100^{\circ} \mathrm{C}$ heattreated fabric. Since sintering does not occur for heat treatment at $\leq 300^{\circ} \mathrm{C}$ the reabsorption is not at all affected whereas in $600^{\circ} \mathrm{C}$ heat-treated fabric, sintering process affects the water reabsorption pattern (figures 2 and 3 )

\subsection{Effect of moisture absorption on volu ne resistivity}

The moisture present in the fabric will decrease the volume resistivity $\left(\rho_{v}\right)$ of the material. Any decrease in the moisture content will increase the resistivity (Rama Chandran et al 1979). It was pointed out earlier that as the post heattreatment temperature increases the moisture content decreases resulting in a corresponding increase in volume resistivity. As can be seen from figure 4 the increase in $\rho_{v}$ is linear with respect to the post heat-treatment temperature.

During the heat treatment apart from the dehydration of silanol groups, porosity is also reduced. Porosity of the fabric also determines the moisture absorbed. Fabrics prepared by leaching in $2 \mathrm{~N} \mathrm{HCl}$ for $3 \mathrm{hr}$ were heat treated at $300,600,900^{\circ} \mathrm{C}$ and then exposed to the atmosphere. Fabrics heated to higher temperature absorb very little moisture and hence $\rho_{v}$ decrease is also less. The decrease in porosity with post heat treatment also affects the mobility of water molecule into the material. Figure 5 shows the effect of post heat treatment temperature on moisture absorption of the E-glass fabric and its volume resistivity and as can be seen it shows the expected trend. The conducting species would be protons as was observed earlier (Tronovcova et al 1977). The diffusion of water in silica has been explained by lattice breaking model (Cockram et al 1969) and diffusion and reaction of molecular water model (Doremus 1969).

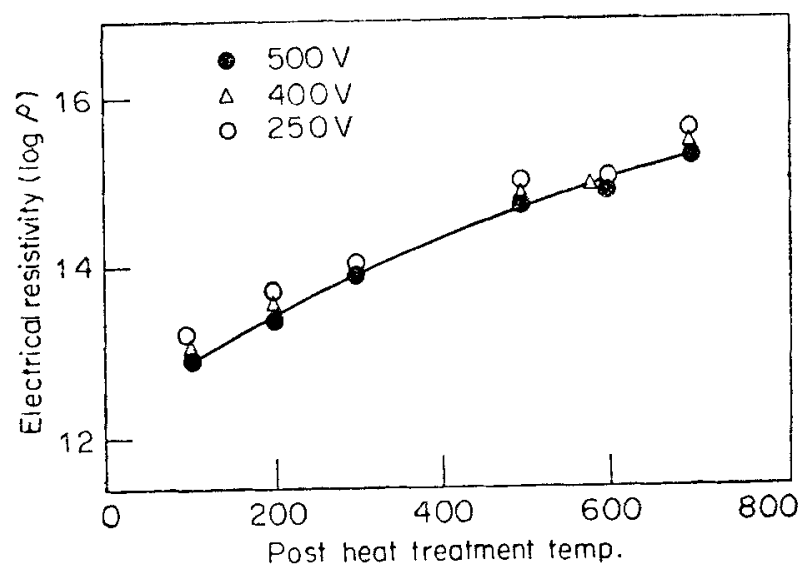

Figure 4. Variation of electrical resistivity with heat-treatment temperature. Fabric soaked in $2 \mathrm{~N}$ acid for $3 \mathrm{hr}$. 


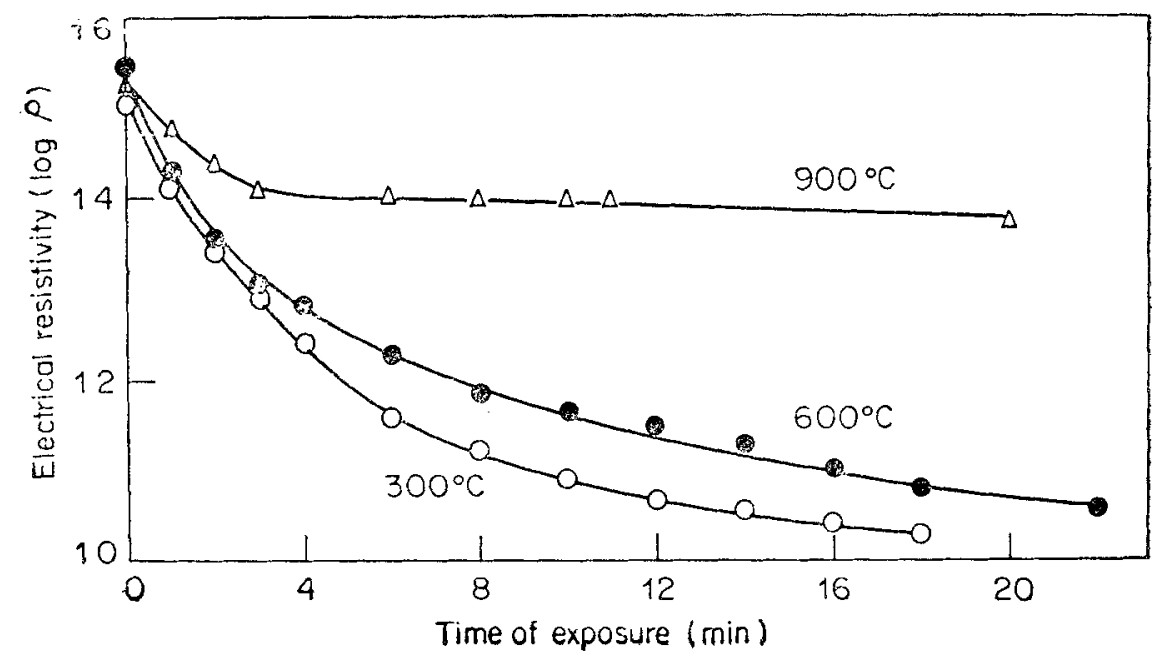

Figure 5. Effect of post heat-treatment on electrical resistivity of fabrics soaked for $3 \mathrm{hr}$ in $2 \mathrm{~N}$ acid.

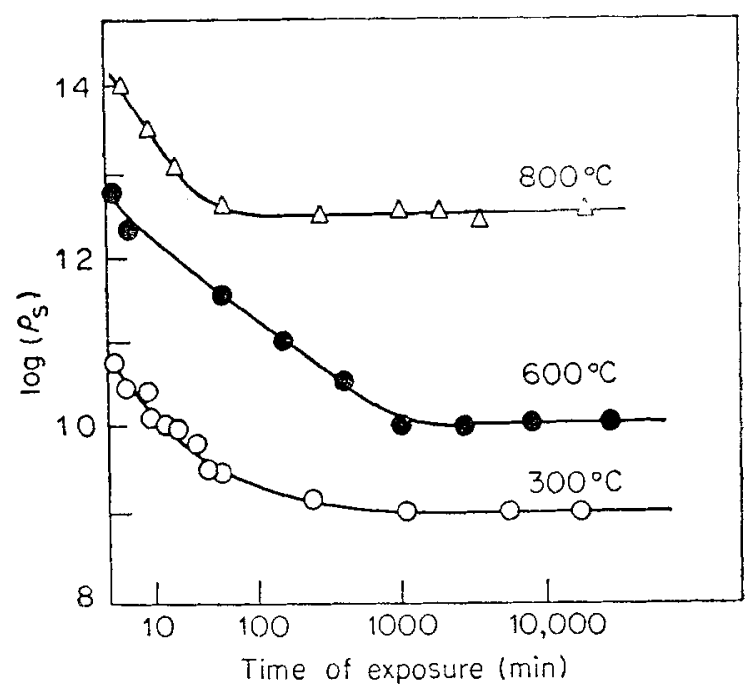

Figure 6. Change in surface resistivity with time exposure for heat treated fabrics.

\subsection{Effect of moisture absorption on surface resistivity}

Figure 6 shows the effect of moisture absorption on surface resistivity $\left(\rho_{\mathrm{s}}\right)$ for fabrics leached in $4 \mathrm{~N} \mathrm{HCl}$ for $6 \mathrm{hr}$ and then heat treated at various temperatures. The change with time was recorded. The decrease is due to the moisture absorption. As the post heat-treatment temperature increases, the moisture absorption rate decreases and hence the decrea $\mathrm{e}$ in $p_{\mathrm{s}}$ varies accordingly. As the moisture absorption increases with time, number of charge carriers also increases. The decrease in $\rho_{\mathrm{s}}$ may also be due to the enhanced and easy mobility of protons in the multimolecular layer of water formed over the silanol groups. 


\section{Conclusions}

E-glass fabric on leaching with $\mathrm{HCl}$ gives rise to silanol groups which become the hydrophilic sites. The moisture absorption of the leached fabric depends on the extent of leaching. The moisture content increases as the ncentration of the leachant increases. The reabsorption of moisture on completely leached and heat-treated samples leads to decrease in both volume and surface resistivities.

\section{References}

Boulos E N and Kreidl N J 1972 J. Can. Ceram. Soc. 47670

Broutman L J and Krock R H 1968 Modern composite materials (New York: Addison Wesley) p. 177

Che-Kvang Wu 1980 J. Am. Ceram. Soc. 63453

Cockram O R, Haider Z and Roberts G J 1969 Phys. Chem. Glasses 1018

Doremus R H 1969 Reactivity of solids (ed) J W Mitchell et al (New York: Wiley Interscience) p. 667

Gut Friend K and Weber H S 1961 SPE Trans. 1191

Hetherington G and Jack K H 1962 phys. Chem. Glasses 3129

Holland L 1966 The properties of glass surfaces (London: Chapman and Hall) Vol. 4, p. 193

Hvang R J 1971 Mechanism of vapour sorption on fibreglass-E Ph. D. thesis, Iowa State University, Iowa, USA

Moulson A J and Roberts J P 1961 Trans. Faraday. Soc. 571208

Rama Chandran B E, Balasubramanian N, Subba Rao G V and Aravamudan $G$ 1981 J. Mater. Sci. 161611

Rama Chandran B E, Pai B C and Balasubramanian N 1979 J. Mater. Sci. 141572

Rama Chandran B E, Pai B C and Balasubramanian N $1980 \mathrm{~J}$. Am. Ceram. Soc. 631

Razouk R I and Salem A S 1948 J. Phys. Colloid. Chem. 521208

Scholze H 1966 The Glass Ind. 47622670

Tronovcova Majkova E, Mariani E and Bohum A 1977 Phys. Chem. Glasses 1018 Young G J $1958 \mathrm{~J}$. Colloid.Sci. 1367 